\title{
Translation of Anzaldúa's book Borderlands in Indian language(s): A challenge in the Indian context
}

\author{
Shilpi Gupta \\ Ph.D. Scholar, Women and Gender Studies, University of Granada, Spain. \\ Email: shilpigupta.jnu@gmail.com
}

\begin{abstract}
:
This paper is a part of a project of translation of the book of Gloria Anzaldúa' Borderlands/ La Frontera: The New Mestiza (1987) in Indian language(s). Borderlands/ La Frontera: The New Mestiza is one of the path-breaking books which came in the time when Afro-American feminism already stood in opposition to white feminism by questioning the Euro-American centric feminism. Anzaldúa started discussing Chicana feminism together with black feminism. Her book Borderlands is a painful but challenging narration of those who live on the 'barbwire' between Mexico and the USA. In defining the border, she goes beyond the physical meaning to its symbolic significance, and one of them is language. Language in her book has been uniquely presented as an identity that is multilingual, creolized, mestiza and subaltern language. Hence, her book is a challenge in the field of translation, especially in Indian context where languages have political, social and historical impact. Considering the above book as a project, I would primarily discuss why this book should be translated considering the Indian context? What are the different ways in which the translation can be defined in translating a text from One-Third world to another Third world? In this process, we find it relevant to revise the language and its relations to power in a postcolonial India, taking into account caste, class, and colonial discourse. This epitome opens a debate to enter into the new political strategies which Gloria Anzaldúa propagates through her book "Nueva Conciencia Mestiza" as moving towards "new language" which could be more inclusive.
\end{abstract}

Keywords: Gloria Anzaldúa, Borderlands/ La Frontera: The New Mestiza, translation, Indian languages, postcolonial India, Politics of Language

Who is to say that robbing people of its language is less violent than war? -Ray Gwyn Smith

\section{Introduction}

This paper is part of a translation project ${ }^{\mathrm{i}}$ of Gloria Anzaldúa's book Borderlands/ La Frontera: The New Mestiza in Indian language(s). In this regard, I would primarily deliberate the process through which an Indian translator, who also speaks Spanish, could translate a Chicana book which is written in mixed language- English, Mexican Spanish, and Nahuatl. Interestingly, neither India is a country of only one language as Hindi of Hindu majority country or English of English colonial country, but multilingual land of hundreds of dialects and languages. Further, Ayesha Jalal suggests that the languages in South Asia from the colonial/modern period in some way worked for the rise

(c) AesthetixMS 2021. This Open Access article is published under a Creative Commons Attribution Non-Commercial 4.0 International License (http://creativecommons.org/licenses/by-nc/4.o/), which permits non-commercial re-use, distribution, and reproduction in any medium, provided the original work is properly cited. For citation use the DOI. For commercial re-use, please contact editor@rupkatha.com. 
of intense nationalist discourse like language and territory, language and caste, language and religion, and language and nation $(2009,6)$. Hence, the translation of a Chicana text in Indian language(s) will revise the language and its relations to power in a postcolonial India, taking into account caste, class, and colonial discourse in order to find a way of translating the book in Indian language(s). Other questions that will be dealt, further, are why should this book be translated considering the Indian context and what are the different ways in which the translation can be defined in translating a text from one-Third world to another Third-world.

\section{Anzaldúa's Borderlands}

Borderlands/ La Frontera: The New Mestiza is one of the path-breaking books written by Gloria Anzaldúa, published in 1987. This book contains seven essays and six sections of poems. The book came at a time when Afro-American feminists already stood in opposition to the mainstream EuroAmerican feminism. To name a few, bell hooks, Kimberley Crenshaw, Angela Davis, Cherrie Moraga, and Barbara Smith came with their black and Chicana feminist position. Anzaldúa's political position grew with them and she started discussing Chicana feminism together with black feminism. Her book This Bridge called my back, published in 1984, was written in collaboration with many other black, women in color, lesbian feminists who challenged the existing mainstream white feminism all over the world. Borderlands, her second book, describes a painful but challenging narration of those (women) who live on the 'barbwire' between Mexico and the USA. While defining the border, she goes beyond the physical meaning to its symbolic significance as 'borderline' and 'border-space.'

Borders are set up to define the places that are safe and unsafe, to distinguish us from them. A border is a dividing line, a narrow strip along a steep edge. A borderland is a vague and undetermined place created by the emotional residue of an unnatural boundary. It is in a constant state of transition. The prohibited and forbidden are its inhabitants. $(1987,3)$

Continuing with her book, in one of the chapters of her book "How to Tame a Wild Tongue," she exhibits the fluidity of a Chicano/a in eight languages in her daily life. She mentions standard English, working-class and slang English, standard Spanish, standard Mexican Spanish, North Mexican Spanish dialect, Chicano Spanish, Tex-Mex and Pachuco. Particularly in her book, she uses three languages namely English, Spanish, and Nahuatl, the indigenous language of Mexico to narrate her auto-ethnography. For instance, in one of the phrases, she uses Spanish and English to write a bilingual sentence.

I want you to speak English. Pa' hallar buen trabajo tienes que saber hablar el inglés bien. Que vale toda tu educación si todavía hablas inglés con un 'accent,' " my mother would say, mortified that I spoke English like a Mexican... $(1987,53-54)$ [I want you to speak English. You have to speak good English in order to find a good job. What is the use of your whole education if you still speak English with a Mexican accent, My mother would say, mortified that I spoke English like a Mexican...]

In that way, her book defines the lingual border-space, which is created at the 'barbwire' between languages. Here, the language which she speaks is Chicano Spanish - a mixed language of Spanish and English. The one which has gone through linguistic terrorism where her people have internalized the fear of speaking the wrong language thinking it is a bastard and illegitimate language and hence, they speak with suspicion and hesitation. However, Anzaldúa calls her language a living language which has developed naturally. "un lenguaje que corresponde a un modo de vivir [a language which corresponds to a way of living]. A language with which they can connect 
their identity to, one capable of communicating the realities and values true to themselves" (1987, 55). In this way Anzaldúa propagates a new language, mixed language in her book.

Further, the language complexity in the book is challenging to one language reader or only English reader, where the Chicano Spanish in the book reminds the presence of Mexicans around English speakers. It is not merely a language but the identity that she has portrayed through her languages- a mixed identity as she compares herself with her language "I am my language" (Anzaldúa, 1987, 58). For instance, she prefers to describe her family in Mexican Spanish, whereas, she refers to gods and goddesses in Nahuatl. English dominates in her book which exposes the occupation of Mexican land by the USA in the $19^{\text {th }}$ century. In this way, Anzaldúa through this language complexity tries to intertwine into the history of her land, her body and her identity. She invites her readers to go through the onerous task of not only to read this text but to understand complex history of the colonization of Aztec land and the indigenous body La Malinche by Spanish colonizer Hérnan Cortés in the 16th century, and the occupation of half of Mexico in 1846 by the US (Anzaldúa, 1987, 7).

Through her book, she lucidly says that if a language is a power apparatus, then it is a tool for others. If it is a metaphor of a dominant canon, then it is a subversive agency that exists simultaneously. It contains both possibilities that depend on the power of articulation of the collective or individual subject. Breaking the language, deforming it in a viable way is a way of appropriation and thus opens a space for differences (1987).

\section{Politics of Language in India: a brief Introduction}

In post-colonial countries like India, English is one of the dominant official languages of communication. India being a colonial land of English colonizers from the $16^{\text {th }}$ century to the mid$2 \mathrm{O}^{\text {th }}$ century, has adopted the modern system of nation formation. The language question was considered an internal part of the process of a modernization project that the newly independent countries like India were destined to follow. So, in order to understand the complex character of language politics in India, it is essential to note the colonial state's interventions in Indian languages and institutionalization of the English language in India. The institutionalization of the English language was part of the hegemonic apparatus between colonizers and the (elite) colonized. Modernization was an elite discourse in post-independence India, and it was carried out in English. Hence, English became the language of modernity and moderns in India. Robert L. Kidder says that the gradation between the high court and Munsif courts in India is also indicative of the gradation of language usages. Accordingly, English became the language of mystification of 'elite discourse,' and 'an adjunct of elitism' $(1976,240)$. The result is that the significant sections of the upper caste elites from regional states and high-class elites, equipped with English education, have been elevated to the national level; quite a few among them have migrated to countries of the developed world. Those who have been left behind are unreconciled to the reorganization of politics brought about by the ascendant middle and intermediate castes and to the consequent loss of their power. Hence, the language difference has created not only the difference between two geographically different places in the same country, but the question of class and caste is embedded with complexity.

Further, a particular focus has been given to the Hindi language, Article 351 of the Indian constitution states that it shall be the duty of the union to promote the spread of the Hindi language "so that it may serve as a medium of expression for all the elements of the composite culture of India" (Sarangi, 2009, 25). In that process, there has been a long debate on the official languages 
since the independence of India in which the Hindi language has occupied a dominating space. Sarangi cites Granville Austin who says that a group of Hindi speaking Assembly members from the provinces of north-central India, led by a hardcore of linguistic extremists, constituted one faction. This group believed that Hindi should be not only the national language under inherent superiority over other Indian languages, but it should replace English for official union purposes immediately or in a short time (Sarangi, 43).

Additionally, Sarangi, in her article, focuses on the surveys which underlines the dominance of Hindi language in post-independent India, and how it has jeopardized the other minor languages. There have been 1652 mother tongues in total reportedly in 1961, out of which 184 mother tongues had fewer than ten thousand speakers each. These 1652 mother tongues were grouped into 114 languages in the census report of 1991. Among them, more than 47 languages were within the fold of the Hindi language alone (2009, 14-15). Now according to the 2011 census, Hindi grew by 161 percent between 1971 and 2011 (Census of India, 2011). The data indicates the loss and absence of several minor and secondary languages that are not being counted separately from Hindi. These minority languages consist of non-scheduled languages, dialects of non-scheduled languages, and those languages represented by less than ten thousand speakers. This indicates the rapid decline of existing linguistic diversity in India as a result of broader processes of cultural homogenization and its impact on the social lives of linguistic communities.

At the same time, the language difference in metropolitan India and rural India is as distant as between two different language speaking countries. It is not only the conflict between languages but conflict in world views and ideologies of the agenda of development in nation-building. Hence, the hierarchization of languages in India is a complex and unique process where English is an elite discourse; Hindi is considered the language of 'mass speaker.' Further, languages also create homogeneity where the linguistic minority in India are based on the hierarchies of caste, class, religion, region, and gender relations.

The complexity increases even more at the regional level, where the use of a regional language as the language of administration in a state and as the medium of instruction in schools is an established policy. For instance, Tamil Nadu disconnects itself from Hindi speaking states as it removes Hindi from its administration and education. Whereas, Uttar Pradesh and Bihar are the testimony of Anti-English Movement calling it, Angrezi Hatao, (Remove English) under the ministry of Mulayam Singh Yadav and Lalu Prasad Yadav (Sonntag, 2009, 235). Especially in the northern states, at the regional level, there has been a long going debate on uses of English and their regional languages in schools. On the one side, private schools use the English language as their medium of instruction where the elite and middle-class children access education. On the other, public schools run on govt funds, use their regional language to teach. Because of such difference in their medium of instruction and the presence of the English language, one cannot deny the fact that a vast majority of children in India continue to receive schooling in the regional language.

An expected consequence of the policy of promoting the regional language for mass education is that it has produced a whole generation of educated youth with little or no exposure to English and whose parents are either illiterate or at best first-generation literate. They are taught English as a subject, but indifferently and at a relatively late stage of their schooling. They show little inclination to use even the little English they may have. When they use it, they do so in a halting way, with a strong regional accent. They have little chance of getting admitted in the charmed circle of the urban youth, who have acquired their English through its use as a medium of education. Thus, for a majority of educated youth, proficiency in English is unattainable, and they 
face unequal competition for social mobility in the society in which English continues to be a mark of education (Sheth,2009, 276).

It may be a lopsided view, but it contains an element of truth when it is said that the continued dominance of English in India has resulted in the emotional alienation of the nonEnglish educated youth from the national mainstream. Niranjana from the feminist perspective also points out the ignored existence of Dalits, their regional languages and their feminisms in the lingual and feminist history of India. Hence young (wo)men of the Third World country like India have this colonial lingual burden to move towards the dominant languages while changing their languages, and taming their tongue and forgetting their lingual and cultural baggage, and become stranger to oneself. Alternatively, to remain silenced and subalterned. This divide between the metropolitan and the vernacular youth brought about by the dual educational streams has given a new twist to the language issue. The question now raised on the result of this duality. Is there a dual presence of mainstream English speakers and regional language speakers, or are there liminal spaces between them?

Many aspirants come from regional languages and start speaking Hindi in their schools and learn English as one of their courses. There is an enormous number of rural students who move out of their lingual border to another zone in order to study or work where they suffer because of their inefficiency of speaking fluent English or having an influence of their regional tone in the Hindi or English language. This lingual state can be majorly found among those who move from regional dialects to Hindi speaking cities and then enter into English of metropolitan universities. In this movement, the regional languages and their speakers are marginalized based on their language accompanied by caste, class, and region. Whereas, this is not implied to the one who moves from city to semi-urban spaces.

Hence, the existence of bilingualism such as 'Hinglish,' Hindi with Bhojpuri accent, or many other idiolects is the lingual identity of many young (wo)men who move from rural to urban India. Within-country, it is treated impure and unofficial way of communication which is teased and humiliated. They internalize the fear of speaking wrong and poor, and they speak with hesitation and suspicion. They are also repeatedly told that their language is wrong. Such a low estimation of how one speaks creates a low estimation of oneself. These speakers are marginalized out of the belt of metropolitan English speaking or other dominating languages. Such terror could be called as creating 'linguistic terrorism,' internalizing the fear of speaking poor, among rural Indians, where Anzaldúa coins the term in her book (58). As a result, from the other side, there is a rising existence of a new kind of language, mixed language, the presence of more than one language, which is used as a dialect. The language is not created by the speakers themselves but it is the result of the imposition of dominant languages. Anzaldúa has brilliantly discussed this lingual border identity from different perspectives such as race, class, and gender. So, it could be expected that most of the rural Indian (women) readers who moved among different languages and carry the baggage of languages and cultures, could connect with the book of Anzaldúa. Else, the translation of the book will be a challenge for those who believe in the purity of language. Hence, the translation of this book will become a medium of expression of the existence of such emerging mixed language.

As far as my experience, as a translator and feminist who has lived 17 years in a small semiurban town, is concerned, the baggage of Bhojpuri language (a dialect of Hindi) and its culture moved with me. There is a continuous movement from Bhojpuri to the Hindi language, where the Bhojpuri accent and language influenced the speaking of Hindi. Sentence structure changed from Bhojpuri to Hindi but the Bhojpuri accent remained embedded in the use of other languages. In no time, English was imposed with the movement from a small semi-urban town to New Delhi. 
Although learning English as part of an urban Indian university and Spanish language as a European foreign language in the professional courses created the fluidity of identity within languages. Multilingual identity privileged me as a reader of Hispanic, English and Hindi writers. However, this constant transition of Bhojpuri speaker into Hindi and Hindi speaker into English made my position ambiguous and questioned by lingual purity and dominance which continues to exist within the dominant lingual discourse. This confused lingual state can be majorly found among those who move from regional dialects to Hindi speaking cities and then they enter into English of metropolitan universities.

This changing paradigm of languages could be better understood through the new discourse of language 'mestiza,' 'creolized' language that the writers like Gloria Anzaldúa have propagated through her book Borderlands. Translation of the text is not just limited to see the indifferent treatment of regional languages in the stream of Hindi, English and other dominating languages but to propose by going beyond the binaries of pure and impure languages. Besides, the focus is to defy the idea of pure language and challenge the imposition on others to fit into the other's languages.

\section{Translation: Construction, Interpretation, and Negotiation}

With the little experience as a feminist reader and speaker of Hindi, English, Spanish, and other regional languages, I tried to translate the text in Hindi. However, Anzaldúa's lingual politics behind her book made me rethink and reconsider the translation of the text. It is not only the language that Anzaldúa played in her text that could be translated in any three languages of India, but it has its rhetoric silences in the form of its cultural, historical and social importance which could not be denied. A translator who is ready to take the risk of entering into the translation needs to understand the complexity of languages in Indian society as well. Besides, the book is enormously loaded with its rhetorical silences, which the writer shares through her essays and poems. Hence the translation of this text demands the decoding of her poems and essays and then again coding them in another language without failing in recreating the lingual conflict of 'original' text and the language in which the text is going to be translated.

The vast space of translation studies has drawn numerous definitions of translation, and some of them are found fundamental in Indian feminist translation studies, which are also the base of this study/translation. Most of the translators of Indian texts admit the complexity of language within the Third World, like India. Tejaswini Niranjana (1998), for instance, points out the ignored existence of Dalits, their regional languages, and their feminisms in the lingual and feminist history of India. These differences among languages within India give the advantage to understand Anzaldúa's rhetorical context of the text. Hence, keeping in mind, the complexity of Hindi with regional language, Anzaldúa's text could be translated for the young feminists who struggle with Hindi and English because of the baggage of their regional language and culture, which they carry with themselves when they move within the country.

Gayatri Spivak, in her text Politics of translation (1992), has brought language in discussion in order to understand the identity. For her, too, language is an identity and hence to create someone's identity or context of the text, it is essential to understand their language. She criticizes the translators who do not intend to enter into the silences of the text and exploit the identity of text. Hence, Spivak defines translation as a part of identity construction that she finds a risky task in the translation because it involves the understanding of not only the language but rhetorical silences behind it (1992, 179). Niranjana, in her text, uses the word 'negotiation' as crucial in 
translation as she defines translation as "a space in which one simultaneously holds on to and negotiates different sorts of languages, conceptual as well as linguistic" (1998, 134). Janika Devika in her text states that the interpretation of concept in the local condition is an integral part of translation and says "Irrespective of whether the translators named faithfulness to the 'original' among their aims, there can be little doubt that the process of translation involved an effort to interpret the concept within local conditions of possibility $(2008,2)$.

Hence translation seen through these texts points towards the construction, negotiation, and interpretation as an essential process in the translation which gives translators more space to understand, interpret, negotiate and construct the text than the mere words like 'being loyal' or 'faithful to the original.'

Moreover, this is a translocal translation project, where the text moves from one periphery to another periphery of the Third World. In this regard, De Lima Costa and Alvarez, Brazilian feminist linguists, assert the need for translation in translocal feminism of the global South since they share the "common context of struggle." They exclaim that "the project of a translocal translation politics is crucial to the decolonial turn and the construction of better "bridging epistemologies" through translation (2014, 558). Márgara Millán, a Mexican feminist and linguist, further, offers us to understand the differences among the feminisms of peripheries. Translation of a feminist text among peripheries cannot be taken granted instead it has to be taken as serious as the translation of any European feminist text to the periphery feminist text because homogenizing of feminist discourse is as dangerous as a colonial game which is played in translating the text as 'safer translator' $(2015,11)$.

\section{Conclusion}

This is especially the motive of translation of not losing the objective of Anzaldúa's writing. The focus should be to understand the rhetorical terms used in her text. The translation should describe those cultural, mythical, historical terms to its new reader without losing the context which Anzaldúa writes and taking into account the difference between the culture, values, languages of two sides. To meet the need of the text, translator should produce the details of the rhetoric silences which could be done through footnotes or endnotes. Hence, translation of the text has to be in transition position, negotiating, interpreting and constructing the text with the comprehension of not falling into the trap of colonial game in the translation. Instead, it should be served with the care of the differences among Chicano/as and Indians to produce a new text for the reader of the language in which the text will be rewritten.

\section{Note}

${ }^{\mathrm{i}}$ The project of translation of the book has been jointly carried by Shilpi Gupta, University of Granada and Gaurav Sushant, VIT, Vellore.

\section{Works Cited}


Anzaldúa, G. (1987). Borderlands/La Frontera: The New Mestiza. Vol. 3. San Francisco: aunt lute books.

Costa, C. L. and Alvarez, S. E. (2014) "Dislocating the sign: Toward a Translocal Feminist Politics of Translation." Signs: Journal of Women in Culture and Society, 39(3). (557 563).

Devika, J. (2008). “Being “in-translation” in a post-colony.” Translation Studies, 1(2) (182-196). doi:10.108o/14781700802113507

Kidder, Robert L. (1976) "Language and litigation in South India." Language and Politics. （240). The Hague: Mouton.

"Language India, States, and Union Territories (Table C-16)." Census of India 2011

"Language Census 2011: Surge in Hindi and English speakers; Tribal language speakers decline." Jagran Josh. Jul 6, 2018, accessed on Feb 2, 2020. https://www.jagranjosh.com/current-affairs/languagecensus-2011-surge-in-hindi-speakers-south-indian-language-and-urdu-speakers-decline-15308690o1-1

Millán, M. (2015). “The traveling of 'gender' and its accompanying baggage: Thoughts on the translation of feminism (s), the globalization of discourses, and representational divides." European Journal of Women's Studies, 23(1). (6-27).

Niranjana, T. (1998). "Feminism and Translation in India: Contexts, Politics, Futures". Cultural Dynamics, 10. (133-146). Retrieved from https://www.academia.edu/2999897/Feminism and Translation in India Contexts Poliics Futures

Ray Gwyn Smith, Moorland is Cold Country, unpublished book.

Sarangi, Asha, ed. (2009). Language and politics in India. Oxford University Press.

Sheth, Dhirubhai L. (2009). "The great language debate: Politics of metropolitan versus vernacular India." Language and politics in India. (Asha Sarangi Ed.). Oxford University Press.

Sonntag, Selma K. (2009). “The political saliency of language in Bihar and Uttar Pradesh.” Language and politics in India. (Asha Sarangi Ed.). Oxford University Press.

Spivak, G. C. (1992) “The Politis of Translation.” Destabilizing Theory. Contemporary Feminist Debates. (Barrett, Michele y Philips, Rose Eds.). (177-200). Cambridge: Polity Press. 